\title{
Upregulation of interleukin-8 and activin A induces osteoclastogenesis in ameloblastoma
}

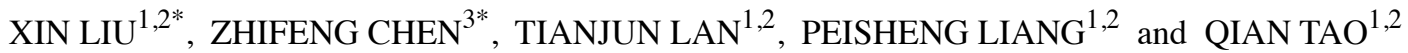 \\ ${ }^{1}$ Department of Oral and Maxillofacial Surgery, Guanghua School of Stomatology, Hospital of Stomatology, \\ Sun Yat-sen University; ${ }^{2}$ Guangdong Provincial Key Laboratory of Stomatology, Guangzhou, \\ Guangdong 510055; ${ }^{3}$ Department of Oral and Maxillofacial Surgery, Nanfang Hospital, \\ Southern Medical University, Guangzhou, Guangdong 510515, P.R. China
}

Received November 17, 2018; Accepted April 10, 2019

DOI: $10.3892 /$ ijmm.2019.4171

\begin{abstract}
Ameloblastoma is a common odontogenic benign tumor located in the jaws and is characterized by severe local bone destruction. The current study aimed to investigate the effect of interactions between tumor cells and bone marrow stromal cells (BMSCs) on osteoclast formation in ameloblastoma. The impact of ameloblastoma/BMSC interactions on cytokine production, gene expression and osteoclastogenesis was examined using an immortalized ameloblastoma cell line that the authors' previously established. The results demonstrated that interactions between ameloblastoma cells and BMSCs increased interleukin (IL)- 8 and activin A secretion by BMSCs. IL-8 expression in BMSCs was modulated by tumor-derived tumor necrosis factor- $\alpha$ and IL- 8 contributed to osteoclast formation not only directly but also by stimulating receptor activator of NF- $\kappa \mathrm{B}$ ligand (RANKL) expression in BMSCs. Activin A secretion in BMSCs was stimulated by ameloblastoma cells via cell-to-cell-mediated activation of c-Jun N-terminal kinase activation, acting as a cofactor of RANKL to induce osteoclast formation and function. The present study highlights the critical role of communication between BMSCs and ameloblastoma cells in bone resorption in ameloblastoma.
\end{abstract}

\section{Introduction}

Ameloblastoma (AM) is a benign but locally invasive odontogenic tumor, accounting for $\sim 1 \%$ of oral tumors and $11-18 \%$

Correspondence to: Dr Qian Tao, Department of Oral and Maxillofacial Surgery, Guanghua School of Stomatology, Hospital of Stomatology, Sun Yat-sen University, 56 Lingyuanxi Road, Guangzhou, Guangdong 510055, P.R. China

E-mail: taoqian@mail.sysu.edu.cn

${ }^{*}$ Contributed equally

Key words: cell-to-cell interaction, ameloblastoma, interleukin-8, activin A, osteoclastogenesis of odontogenic tumors (1). In the 4th edition of the World Health Organization Classification of Head and Neck Tumors published in 2017, AM was classified into three main types: AM, unicystic, and extraosseous/peripheral types, among which classic AM is the most common accounting for $91 \%$ of all cases (2). AM initially presents as a concealed central bone lesion, which gradually leads to bone and tooth root resorption. If ignored further, the bone can become perforated and the tumor will eventually invade the soft tissue (3).

Previous studies of the invasiveness of AM in the bone have mainly evaluated the following aspects: Cell cycle proliferation $(4,5)$, apoptosis $(6,7)$, invasiveness (8) and matrix metalloproteinases (9-11). However, bone represents a particularly mineralized harsh environment for tumor progression characterized by a high rigidity and modulus. Although the invasive capacities of tumor cells are important for tumor progression, the stimulation of bone resorption by tumor cells is required to invade the skeleton (12). It is widely accepted that osteolytic lesions predominantly result from increased osteoclast recruitment, activation, differentiation and function $(13,14)$. In the current study, numerous osteoclasts were detected in osteolytic lesions of AM, which were located not only adjacent to tumor cells but also at more distant sites, indicating the potential role of osteoclast formation in AM development in the bone. However, coculture of osteoclast precursors with AM cells resulted in only a slight increase in osteoclastogenic activity. Therefore, whether other possible mechanisms underlie osteoclast activation in AM was evaluated.

Previously, interactions between tumor cells and cells in the bone microenvironment have been proposed as potential drivers of tumor progression in the bone (15). The understanding of these interactions has mostly been derived from studies of bone metastatic diseases, including breast cancer $(16,17)$, prostate cancer (18) and bone malignancies including multiple myeloma (19-24). During these interactions, the bone marrow microenvironment is enriched by a variety of inflammatory factors including parathyroid hormone-associated protein, tumor necrosis factor- $\alpha$ (TNF- $\alpha$ ), interleukin 1 (IL)-1, IL-6, IL-8, IL-11, activin A and receptor activator of NF- $\mathrm{B}$ ligand (RANKL) (16-26), which further stimulate tumor growth and osteoclastogenesis or inhibit osteoblast formation, supporting tumor progression in the bone. 
RANKL is the final extracellular mediator that promotes osteoclast precursors to differentiate into mature osteoclasts in the presence of macrophage-colony stimulating factor (M-CSF), an indispensable factor for early development of osteoclasts and survival of mature osteoclasts $(27,28)$. Bone resorbing factors, including IL-1, IL-6, IL-8, IL-11 and IL-17, have been reported to trigger RANKL expression in bone marrow stromal cells $(14,15,29)$. Osteoprotegerin (OPG) produced by stromal cells acts as a soluble decoy receptor for RANKL and prevents osteoclast formation by interfering with the interactions between RANKL and its receptor RANK $(27,28)$.

In AM, communication between tumor cells and host cells and the underlying cellular and molecular mechanisms remain poorly understood. A previously study by Fuchigami et al (30) suggested that direct interactions between tumor cells and stromal fibroblasts support proliferation of tumor cells in AM.

The aim of the present study was to clarify the role of the interactions between AM cells and bone marrow stromal cells in osteoclastogenesis. The present study provides experimental evidence demonstrating that IL- 8 and activin A were induced in stromal cells following interacting with AM cells. These two factors, in combination with RANKL, served critical roles in osteoclastogenesis in AM.

\section{Materials and methods}

Reagents. Anti-TNF- $\alpha$, activin A and IL- 8 antibodies, as well as recombinant RANKL, OPG, activin A and nonspecific mouse immunoglobulin (Ig)G were purchased from R\&D Systems, Inc., (Minneapolis, MN, USA). Anti-RANKL, cathepsin K, and acid phosphatase 5, tartrate resistant (TRAP) antibodies were purchased from Abcam (Cambridge, UK). Anti-JUN N-terminal kinase (JNK), anti-phosphorylated (p)-JNK and anti-nuclear factors of activated T-cells (NFATc-1) antibodies were purchased from Cell Signaling Technology, Inc., (CST; Danvers, MA, USA). Recombinant human IL-8 and recombinant murine M-CSF were purchased from Sino Biological (Beijing, China). The JNK pathway inhibitor SP600125 was purchased from Sigma-Aldrich (Merck KGaA, Darmstadt, Germany).

Tissue samples and cell culture. The AM tissues were obtained from 2 male patients ( 27 and 29 years old) and 2 female patients (23 and 24 years old) treated at the Department of Oral and Maxillofacial Surgery (Hospital of Stomatology, Sun Yat-sen University, Guangzhou, China) from June 2017 to February 2018. Informed consent was obtained according to a protocol approved by the Ethical Committee of the Guanghua School of Stomatology, Hospital of Stomatology and Sun Yat-sen University [Guangzhou, China; ERC-(2017)-5]. Principles outlined in the Declaration of Helsinki were followed. All AM tissues were resected from the mandible, two were from plexiform and two were from follicular AM (Table SI). Normal bone tissue was obtained from a 24-year-old female patient with dento-maxillofacial deformities during the orthognathic surgery.

Primary culture of AM cells was performed as previously described (31). Briefly, the specimen was diced into pieces at an approximate size of $1 \mathrm{~mm}^{3}$ following removing the soft connective tissue, placed into plates coated with collagen I
(Invitrogen; Thermo Fisher Scientific, Inc., Waltham, MA, USA) and incubated at $37^{\circ} \mathrm{C}$ in a $5 \%(\mathrm{v} / \mathrm{v}) \mathrm{CO}_{2}$ atmosphere for $5 \mathrm{~h}$. Dulbecco's modified Eagle's medium (DMEM; Gibco; Thermo Fisher Scientific, Inc.) containing 15\% (v/v) fetal bovine serum (FBS; Gibco; Thermo Fisher Scientific, Inc.) was added and used for subculture of the proliferative cells. The epithelial cells were purified and collected with a differential adhesion method.

Mouse bone marrow-derived monocyte/macrophage precursor cells (BMMs) were isolated as previously described with slight modifications (32). Briefly, bone marrow cells were collected from the femur and tibiae of 126 -week-old female C57BL/6J mice (mean weight, $17.2 \mathrm{~g}$ ). The mice were purchased from the Laboratory Animal Center of Sun Yat-sen University. Following washing, the cells were resuspended in $\alpha$-minimum essential medium (Gibco; Thermo Fisher Scientific, Inc.) containing 10\% FBS. Following $16 \mathrm{~h}$ of culture, the nonadherent cells were collected and incubated in M-CSF $(25 \mathrm{ng} / \mathrm{ml})$ at a density of $3 \times 10^{5}$ cells $/ \mathrm{ml}$ in flasks. The cells were used as BMMs following 3 days of culture. The study was performed in accordance with the Guidelines laid down by the National Institute of Health (Bethesda, MD, USA) in the USA regarding the care and use of animals for experimental procedures, and in accordance with local laws and regulations. Adequate measures were taken to minimize the pain or discomfort of the mice. The experiment was approved by the Institutional Animal Care and Use Committee of Sun Yat-sen University (IACUC-DB-2017-0605).

The AM cell line, hTERT-AM, was previously established by the authors' group (31). HS-5, a human bone marrow stromal cell line, was purchased from the American Type Culture Collection (Manassas, VA, USA). The cells were cultured in DMEM containing $10 \% \mathrm{FBS}$ at $37^{\circ} \mathrm{C}$ in a $5 \%(\mathrm{v} / \mathrm{v}) \mathrm{CO}_{2}$ atmosphere.

Cocultures of hTERT-AM cells with HS-5 cells. The hTERT-AM cells and HS-5 cells were directly cocultured in 1:1 ratio or independently cultured at a density of $2.5 \times 10^{5}$ cells $/ \mathrm{ml}$ for $24 \mathrm{~h}$. For indirect cocultures, HS-5 cells $\left(1.5 \times 10^{5}\right.$ cells) were seeded in the lower chamber of a 24-transwell plate (0.4-mm pore size; Corning-Costar; Conig, Inc., Corning, NY, USA) and $100 \mu 1$ medium containing $5 \times 10^{4} \mathrm{AM}$ cells was added to the upper chamber. Cells were cultured for $24 \mathrm{~h}$. The culture media (CM) was collected and stored at $-80^{\circ} \mathrm{C}$ until use. Cells were used for RNA extraction.

Cytokine array. A commercial antibody-based protein microarray assay was performed using G-Series Human Bone Metabolism Array 1 (RayBiotech Life, Norcross, GA, USA). In brief, array glass slides were incubated in serum-free media from HS-5 cultures, hTERT-AM/HS-5 cocultures and hTERT-AM cultures $(500 \mu \mathrm{g} / \mathrm{ml})$ for $2 \mathrm{~h}$. Following washing, the glass slides were incubated with a cocktail of 31 biotinylated antibodies and the remaining experimental procedure was carried out following the manufacturer's protocol. The intensity of the signal was normalized to that of the internal positive control.

ELISA. The serum-free medium from cell cultures were collected and the level of TNF- $\alpha$ (cat. no. CSB-E04740h; Cusabio, Wuhan, China), IL-8 (cat. no. D8000C; R\&D Systems, 
Inc.), and activin A (cat. no. DAC00B; R\&D Systems, Inc.) were analyzed in accordance with the manufacturer's protocol.

Reverse transcription-quantitative polymerase chain reaction (RT- $q P C R)$. Total RNA was extracted using TRIzol (Invitrogen; Thermo Fisher Scientific, Inc.) and reverse synthesized to cDNA using a PrimeScript RT Reagent kit (Takara Bio Inc., Otsu, Japan). The following thermal cycling steps were used: $37^{\circ} \mathrm{C}$ for $15 \mathrm{~min}, 85^{\circ} \mathrm{C}$ for $5 \mathrm{sec}$, and store at $4^{\circ} \mathrm{C}$. GAPDH was used as internal control. The primers used in the present study are presented in Table SII. Amplification of the cDNA template was conducted using LightCycler 480 SYBR-Green I Master (Roche Diagnostics, Basel, Switzerland). PCR cycles were run as follows: $95^{\circ} \mathrm{C}$ for $5 \mathrm{~min}, 40$ cycles of $95^{\circ} \mathrm{C}$ for $10 \mathrm{sec}, 60^{\circ} \mathrm{C}$ for $20 \mathrm{sec}$ and $72^{\circ} \mathrm{C}$ for $20 \mathrm{sec}$. Finally followed by $95^{\circ} \mathrm{C}$ for $5 \mathrm{sec}$ and $65^{\circ} \mathrm{C}$ for $1 \mathrm{~min}$. Following RT-PCR, the PCR products were separated on a $2 \%$ agarose gel and stained with a new type of DNA dye GoldView (cat. no. G8140; Beijing Solarbio Science \& Technology Co., Ltd., Beijing, China), which is an ideal substitute for ethidium bromide. Expression of each gene was normalized to that of GAPDH as a loading control.

Western blot analysis. Total cellular proteins were extracted with Radioimmunoprecipitation assay lysis buffer (cat. no. P0013B; Beyotime Institute of Biotechnology, Shanghai, China) containing $10 \mathrm{mg} / \mathrm{ml}$ aprotinin, $10 \mathrm{mg} / \mathrm{ml}$ leupeptin and $100 \mathrm{mM}$ PMSF. The bicinchoninic acid assay was used for protein quantification. The aliquots (containing $40 \mu \mathrm{g}$ protein) were separated by $8 \%$ SDS-PAGE, transferred to polyvinylidene difluoride membrane. The membranes were incubated at $4^{\circ} \mathrm{C}$ overnight with antibodies against TRAP (cat. no. ab191406; Abcam; 1:1,000), NFATc-1 (cat. no. 8032; CST; 1:1,000), Cathepsin K (cat. no. ab187647; Abcam; 1:1,000), RANKL (cat. no. ab97864; Abcam; 1:1,000), JNK (cat. no. 9252; CST; $1: 1,000)$ and p-JNK (cat. no. 4668; CST; $1: 1,000)$. Anti- $\beta$-actin (cat. no. 4970; CST; 1:1,000) was used as a loading control. After washing, the membranes were incubated with IRDye ${ }^{\circledR}$ 800CW goat anti-Rabbit IgG (cat. no. 926-32211; LI-COR Biosciences, Lincoln, NE, USA; 1:10,000) or Alexa Fluor ${ }^{\circledR}$ 680 goat anti-rabbit IgG (cat. no. ab175773; Abcam; 1:10,000) for $1 \mathrm{~h}$ at room temperature. The target proteins were visualized and quantification was performed with the Odyssey Clx Infrared Imaging System (LI-COR Biosciences) and Image Studio 5.0 software (LI-COR Biosciences).

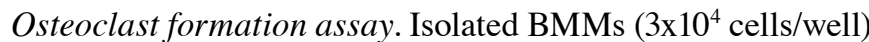
were cultured in a 96-well plate in medium containing M-CSF (25 ng/ml), RANKL (50 ng/ml), IL-8 (100 ng/ml), activin A (50 ng/ml), the culture mediums of hTERT-AM cells, HS-5 cells and the coculture medium with or without corresponding antibodies for 5 days. The cultures were fed every 2 days with fresh medium. To detect osteoclast formation, the cells were subjected to TRAP staining using an Acid Phosphatase Leukocyte kit (Sigma-Aldrich; Merck KGaA). In addition, multinucleated TRAP-positive cells ( $\geq 3$ nuclei) were counted as osteoclasts.

Pitformation assay. BMMs ( $3 \times 10^{4}$ cells/well) were seeded onto $6 \mathrm{~mm}$-diameter dentin slices in 96-well plates and cultured in medium containing M-CSF (25 ng/ml), RANKL (50 ng/ml) with or without activin A $(50 \mathrm{ng} / \mathrm{ml})$, or the CM from HS-5 cells, hTERT-AM cells and HS-5/hTERT-AM cocultures for 15 days. CM was changed every 2 days. The cells were lysed with $0.25 \%$ ammonia water and the slices were stained with toluidine blue for $4 \mathrm{~min}$ at room temperature. To evaluate bone resorption, the areas covering the pit were calculated by counting the number of mesh squares $(100 \times 100 \mu \mathrm{m})$ with a light microscope (magnification, x100; Olympus Corporation, Tokyo, Japan).

Statistical analysis. Statistical analysis was conducted using SPSS version 23.0 software (IBM, Corps., Armonk, NY, USA). Data are presented as the mean \pm standard deviation. Student's t-tests were used in two-group comparisons. One-way analysis of variance with multiple comparisons followed by Tukey's test was used for multiple groups comparisons. All tests were two-tailed and a value of $\mathrm{P}<0.05$ was considered to indicate a statistically significant difference. Each experiment was performed in triplicate.

\section{Results}

Osteolysis and osteoclasts in AM. A total of two subtypes of AM were first tested for their ability to form osteolytic lesions and induce osteoclast formation. The histological examination results indicated a follicular and a plexiform AM, respectively (Fig. 1A). The sections were then stained with TRAP, a specific enzyme of osteoclasts. TRAP-positive osteoclasts were located adjacent to tumor cells, but were more commonly demonstrated at more distant sites from tumor cells, forming resorption pits. However, the normal bone demonstrated no TRAP-positive cells and a smooth cortical bone surface (Fig. 1B). Additionally, The AM tissues and primary AM cells as well as hTERT-AM cells were screened for the expression of osteoclast-activating factors including RANKL, M-CSF, IL- $1 \alpha$, IL-1 $\beta$, TNF- $\alpha$, IL- 6 and IL- 8 by RT-PCR. Due to different sources or conditions of the tissues and cells, these factors demonstrated various expression levels among the specimens; however, RANKL expression was only detected in AM tissues rather than in AM cells (Fig. 1C).

Coculture medium of AM cells and bone marrow stromal cells induces osteoclast differentiation and function. Mouse BMMs were treated with culture media from hTERT-AM. A slightly increased number of TRAP-positive cells was observed [Fig. 2A(c)], suggesting that the soluble factors released from AM cells have a limited potential to stimulate osteoclast formation. It was observed that osteoclasts were mostly located in the bone marrow far from the tumor cells, which prompted the investigation of whether cells in the bone microenvironment, particularly BMSCs, serve a role in osteoclastogenesis in AM. Therefore a cell-to-cell coculture of hTERT-AM cells, HS-5 cells and a human BMSC line was established and the coculture medium was added to the culture of mouse BMMs. Notably, the average number of TRAP-positive cells was identified to be significantly increased when mouse BMMs were treated with culture medium from the coculture $[\mathrm{P}<0.05$; Fig. $2 \mathrm{~A}(\mathrm{~d})$ and $\mathrm{B}]$. However, BMSCs plated in the absence of hTERT-AM cells did not induce osteoclast formation [Fig. 2A(b)]. A pit formation assay was further performed to investigate the potential 
A

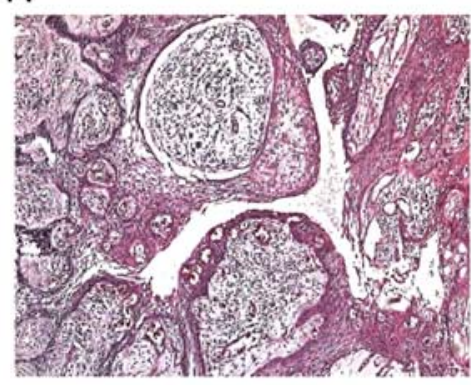

FT

B

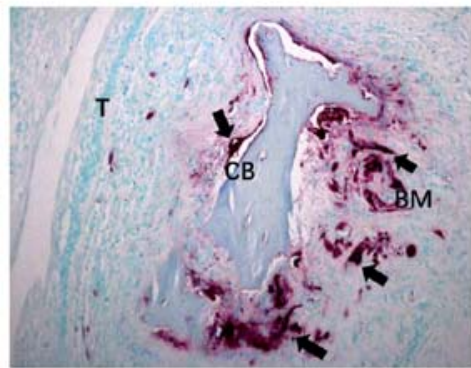

FT
C

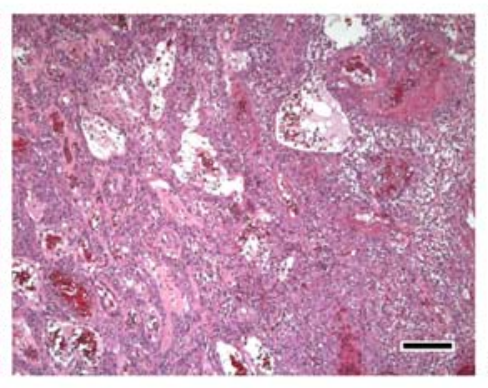

PT

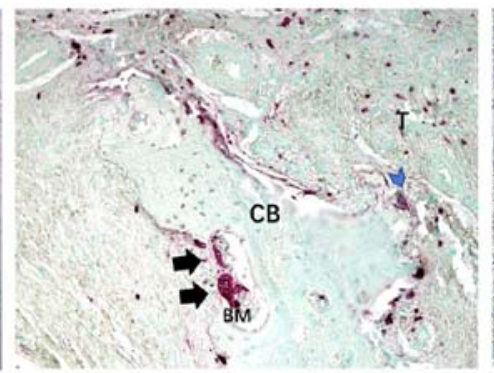

PT
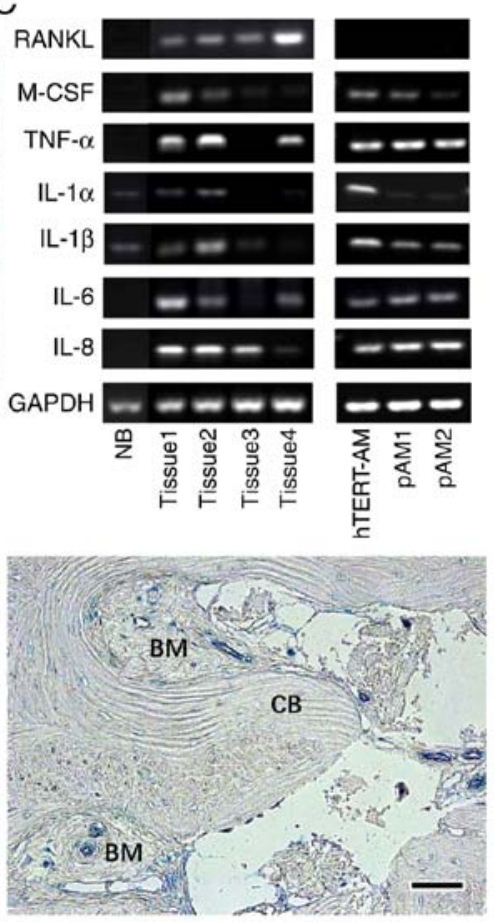

NB

Figure 1. AMs develop osteolytic lesions and induce osteoclastogenesis. (A) Hematoxylin and eosin staining of histological sections of the tumors from two patients: One FT and a PT. Scale bar, $250 \mu \mathrm{m}$. (B) TRAP-positive cells were presented on the surface of the bone adjacent to tumor cells (blue arrowhead), but more commonly located at a distant site from the tumors (black arrow). Scale bar, $250 \mu \mathrm{m}$. (C) Expression of osteoclast-activating factors in AM tissues and cells. The polymerase chain reaction products were separated on a $2 \%$ agarose gel and stained with gold view and expression of each gene was normalized to GAPDH, which was used as a loading control. The experiment was performed in triplicate. PAM, primary AM cells; FT, follicular type; PT, plexiform type; NB, normal bone tissue; T, tumor; CB, cortical bone; BM, bone marrow; RANKL, receptor activator of NF- $\mathrm{B}$ ligand; IL, interleukin; TNF, tumor necrosis factor; M-CSF, macrophage-colony stimulating factor; AM, ameloblastoma; TRAP, acid phosphatase 5, tartrate resistant.

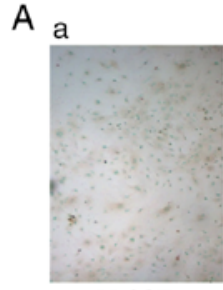

M-CSF
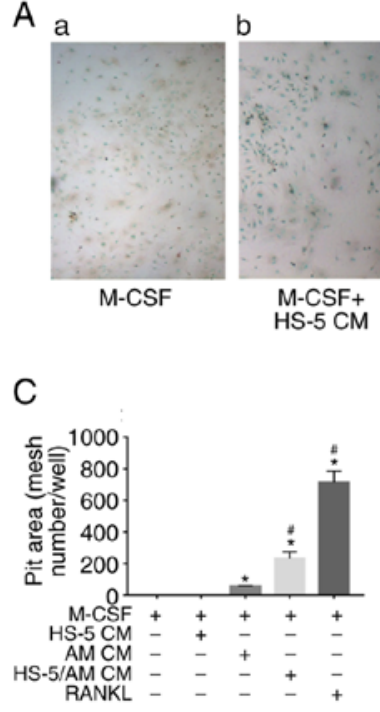

d

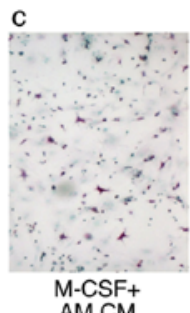

$\mathrm{MM}$ CM

$\mathrm{D}$

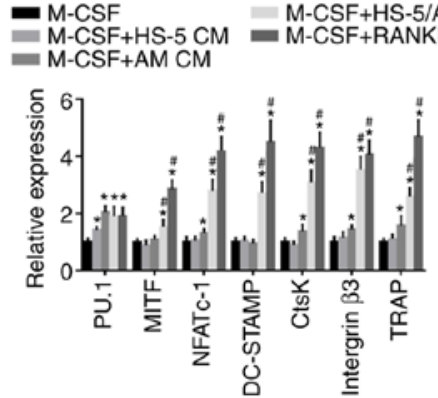

B

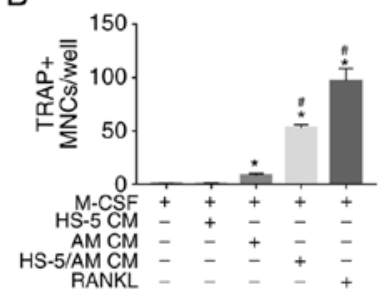

E

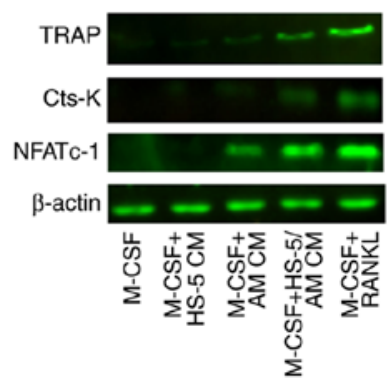

Figure 2. Coculture medium of hTERT-AM cells and HS-5 cells increases osteoclast formation and function. (A) Mouse BMMs (3x10 4 cells/well) were cultured in osteoclastogenic medium with $25 \mathrm{ng} / \mathrm{ml} \mathrm{M}-\mathrm{CSF}$, or in the same medium containing either $50 \mathrm{ng} / \mathrm{ml}$ RANKL or CM from HS-5 cells, hTERT-AM cells and hTERT-AM/HS-5 cultures at $50 \%$ dilution for 5 days. Scale bar, $250 \mu \mathrm{m}$. (B) TRAP positive multinucleated cells ( $\geq 3$ nuclei) were counted as mature osteoclasts. (C) BMMs were seeded onto $6 \mathrm{~mm}$-diameter dentin slices in 96 -well plates and cultured in medium as described above for 15 days. Culture media was altered every 2 days. Then, pit areas were measured by counting mesh numbers. (D) mRNA expression of PU.1, MITF, NFATc-1, DC-STAMP, cathepsin $\mathrm{K}$, integrin $\beta 3$ and TRAP in BMMs were determined by reverse transcription-quantitative polymerase chain reaction. ${ }^{*}<0.05$ vs. BMMs treated with M-CSF, ${ }^{\text {}} \mathrm{P}<0.05$ vs. BMMs treated with M-CSF+hTERT-AM CM. (E) NFATc-1, cathepsin K and TRAP proteins in BMMs were detected by western blotting. $\beta$-actin was used as loading control. The experiment was performed in triplicate. CtsK, cathepsin K; M-CSF, macrophage colony stimulating factor; TRAP, acid phosphatase 5, tartrate resistant; NFATc-1, nuclear factors of activated T-cells; BMMs, bone marrow-derived monocyte/macrophage precursor cells; CM, conditioned medium; RANKL, receptor activator of NF- $\kappa \mathrm{B}$ ligand. 

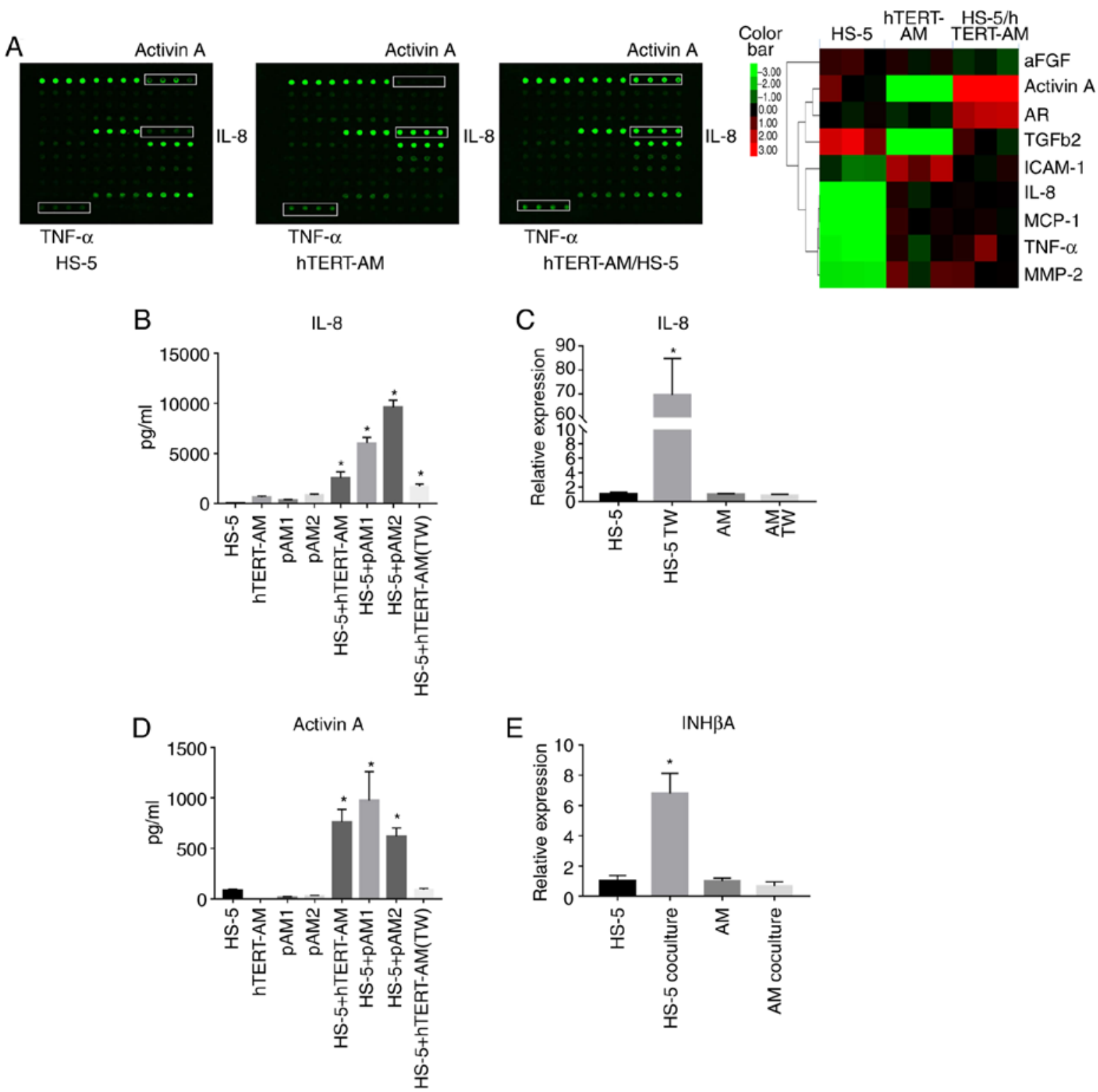

Figure 3. Interactions between AM cells and BMSCs stimulated secretion of IL-8 and activin A. (A) Cytokine array of the conditioned media of HS-5 cells, hTERT-AM cells and the coculture of the two cell types. The hTERT-AM cells and HS-5 cells were directly co-cultured in 1:1 ratio or independently cultured at a density of $2.5 \times 10^{5}$ cells $/ \mathrm{ml}$ for $24 \mathrm{~h}$, the serum-free mediums were collected for array analysis. A1-A4: POS1; A5-A8: POS2; A9-A12: Activin A; B1-B4: FGF-1; B5-B8: Amphiregulin; B9-B12: bFGF; C1-C4: BMP-4; C5-C8: BMP-9; C9-C12: E-Selectin; D1-D4: CD54; D5-D8: IGF-1; D9-D12: IL-1a; E1-E4:

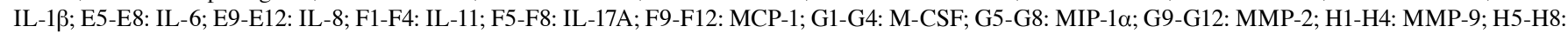
MMP-13; H9-H12: Osteoactivin; I1-I4: P-Cadherin; I5-I8: RANK; I9-I12: Stromal-cell derived factor-1 $\alpha$; J1-J4: Sonic hedgehog-N; J5-J8: TGF31; J9-J12: TGF32; K1-K4: TNF- $\alpha$; K5-K8: CD106; K9-K12: CDH5. A heat map (right) demonstrating the semiquantitative results of cytokine levels. (B) Protein levels of IL-8 in the serum-free culture media from AM cells (hTERT-AM cells, primary AM cells), HS-5 cells or direct or Transwell co-cultures measured by ELISA. ${ }^{*} \mathrm{P}<0.05$ vs. wells containing HS-5 cells or the corresponding AM cells. (C) hTERT-AM cells and HS-5 cells were cultured separately with a Transwell plate for $24 \mathrm{~h}$, RT-qPCR was performed to detect relative mRNA expression of IL-8 to GAPDH. ${ }^{*} \mathrm{P}<0.05$ vs. HS-5 monoculture. (D) Protein levels of activin A in the serum-free culture media from AM cells (hTERT-AM cells, primary AM cells), HS-5 cells or direct or Transwell co-cultures measured by ELISA. "P<0.05 vs. wells containing HS-5 cells or the corresponding AM cells. (E) hTERT-AM cells and HS-5 cells were cocultured for $24 \mathrm{~h}$. Following cell separation, RT-qPCR was performed to detect relative mRNA expression of INH $\beta$ A to GAPDH. "P<0.05 vs. HS-5 monoculture. The experiment was performed in triplicate. pAM, primary AM cells; RT-qPCR, reverse transcription-quantitative polymerase chain reaction; IL, interleukin; CD, cluster of differentiation; BMP, bone morphogenic protein; AM, ameloblastoma; MMP, matrix metalloproteinase; TGF, transforming growth factor; TNF, tumor necrosis factor; bFGF, basic fibroblast growth factor; SDF, stromal-cell derived factor.

of the multi-nucleated cells to resorb calcified tissue. The results demonstrated that the formation of resorption pits was seen on the dentin slices treated with hTERT-AM CM or HS-5/ hTERT-AM CM and the pit area of wells containing HS-5/hTERT-AM CM was $\sim 4$-fold greater than those seeded with hTERT-AM CM (Fig. 2C). Furthermore, mRNA expression of regulatory genes of osteoclast proliferation (PU.1), differentiation (NFATc-1), fusion (DC-STAMP and MITF) and function (Cathepsin $\mathrm{K}$, integrin $\beta 3$, and TRAP) were identified to be elevated in BMMs following treatment with HS-5/AM CM (Fig. 2D). These, in combination with an elevated protein level of NFATc-1, Cathepsin K and TRAP (Fig. 2E), which suggested that interactions between AM cells and BMSCs are essential for osteoclast differentiation and function. 
A

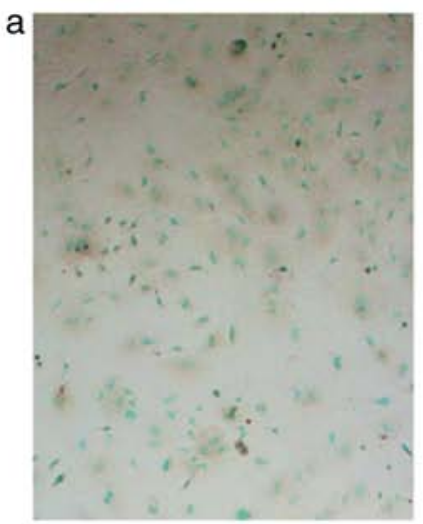

d

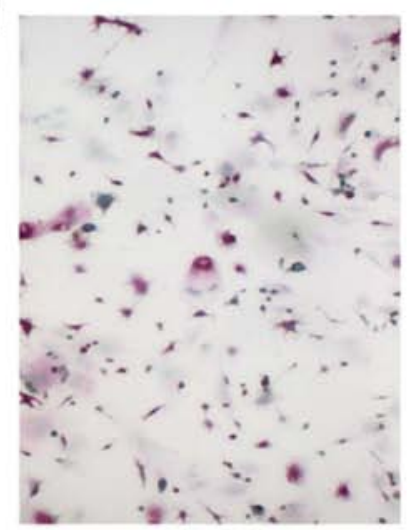

b

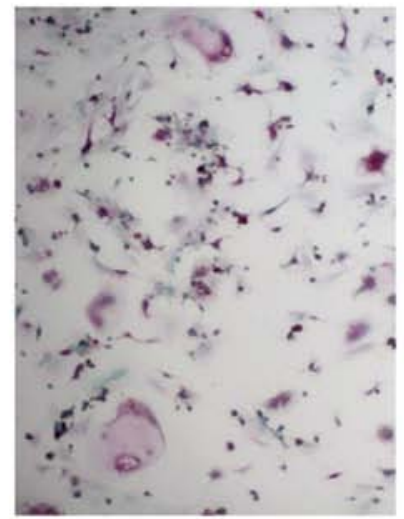

e

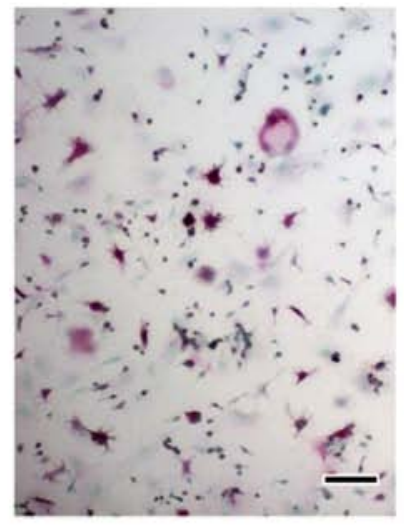

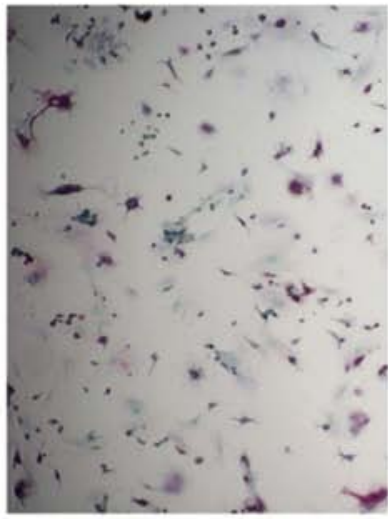

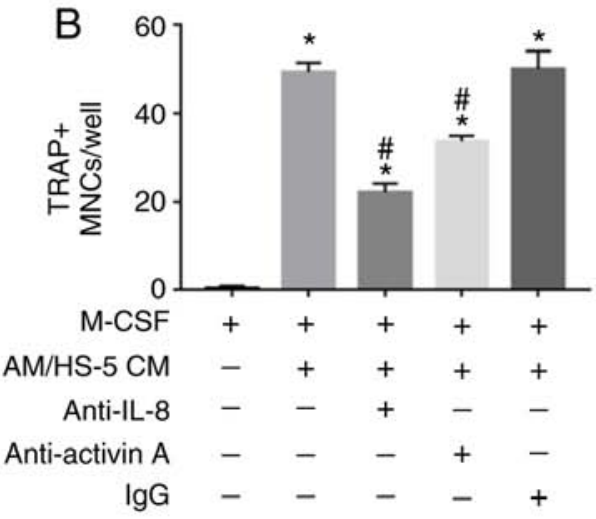

Figure 4. Neutralization of IL-8 or activin A resulted in decreased osteoclastogenesis induced by AM/bone marrow stromal cells CM. (A) Mouse bone marrow-derived monocyte/macrophage precursor cells were cultured in osteoclastogenic medium with $25 \mathrm{ng} / \mathrm{ml} \mathrm{M}-\mathrm{CSF}$, or in the same medium containing the CM from HS-5/hTERT-AM cocultures at 1:1 dilution. Anti-IL-8 antibody $(1 \mu \mathrm{g} / \mathrm{ml})$ or anti-activin A antibody (100 ng/ml) was added to some of the CM-containing wells, the cells were cultured for 5 days. (a) +M-CSF,(b) +M-CSF+AM/HS-5 CM, (c) +M-CSF+AM/HS-5 CM+anti-IL-8, (d) +M-CSF+AM/HS-5 CM+anti-activin A and (e) +M-CSF+AM/HS-5 CM+ immunoglobulin G. Scale bar, $250 \mu \mathrm{m}$. (B) The number of TRAP+ MN cells ( $\geq 3$ nuclei) was indicated. ${ }^{*} \mathrm{P}<0.05$ vs. cells treated with $\mathrm{M}-\mathrm{CSF},{ }^{\text {"}} \mathrm{P}<0.05$ vs. wells containing M-CSF+AM/HS-5 CM. The experiment was performed in triplicate. IL, interleukin; M-CSF, macrophage-colony stimulating factor; CM, conditioned media; AM, ameloblatoma; TRAP, acid phosphatase 5, tartrate resistant; MN, multinucleated.

Interactions between AM cells and BMSCs triggers $I L-8$ and activin $A$ expression. A total of 31 cytokines and growth factors potentially involved in bone metabolism were screened for in the culture media of monoculture of hTERT-AM cells, HS-5 cells and coculture of the two cell lines using a cytokine array. The analysis indicated that certain cytokines were relatively abundant in the HS-5/ hTERT-AM cell coculture medium. Notably, the expression of IL- 8 and TNF- $\alpha$ in the CM of hTERT-AM cells was significantly increased compared with HS-5 cells and a markedly elevated level of activin A was observed in the coculture medium of the two cell lines (Fig. 3A and Table SIII). These three factors were previously observed to be involved in the process of bone resorption $(13,33,34)$.

To validate the findings of the cytokine array, IL-8 levels were quantified by ELISA in the 24-h serum-free culture media from the HS-5 cells, AM cells, or coculture of the two cell types. The results revealed that AM cells secreted increased amounts of IL-8 compared with HS-5 cells and a dramatic increase in the production of IL-8 protein was observed following direct or indirect co-culture of the two cell types (Fig. 3B). To define the source of IL- 8 in the coculture, RT-qPCR was performed to compare IL-8 expression in AM cells and HS-5 cells cultured separately using a Transwell plate. The results revealed a significant increase in IL-8 expression in HS-5 cells following indirect coculture with hTERT-AM cells, whereas IL-8 expression in hTERT-AM cells remained nearly unchanged $(\mathrm{P}<0.05$; Fig. 3C). These data indicate that AM cells stimulated the IL-8 secretion of BMSCs either though cell-cell contact or soluble factors

In addition, activin A production was observed to be relatively high in HS-5 cells, but was nearly undetectable in AM cells. Only a direct interaction between AM and HS-5 cells could increase activin A production in the coculture medium (Fig. 3D). To investigate the source of activin A, RT-qPCR was used to examine the expression levels of inhibin- $\beta \mathrm{A}$ subunits, in which activin $\mathrm{A}$ is a dimer. The results indicated that the upregulated activin A was derived from BMSCs (Fig. 3E). These findings suggest that cell-to-cell contact was essential for triggering activin A secretion in BMSCs.

Furthermore, ELISA analysis verified increased production of TNF- $\alpha$ in AM cells compared with in HS-5 cells and that coculture of AM and HS-5 cells did not lead to alteration in TNF- $\alpha$ protein level (Fig. S1).

Neutralization of $I L-8$ or activin A results in decreased osteoclastogenesis induced by AM/BMSCs CM. To investigate the role of AM/BMSCs CM-derived IL-8 and activin A in 

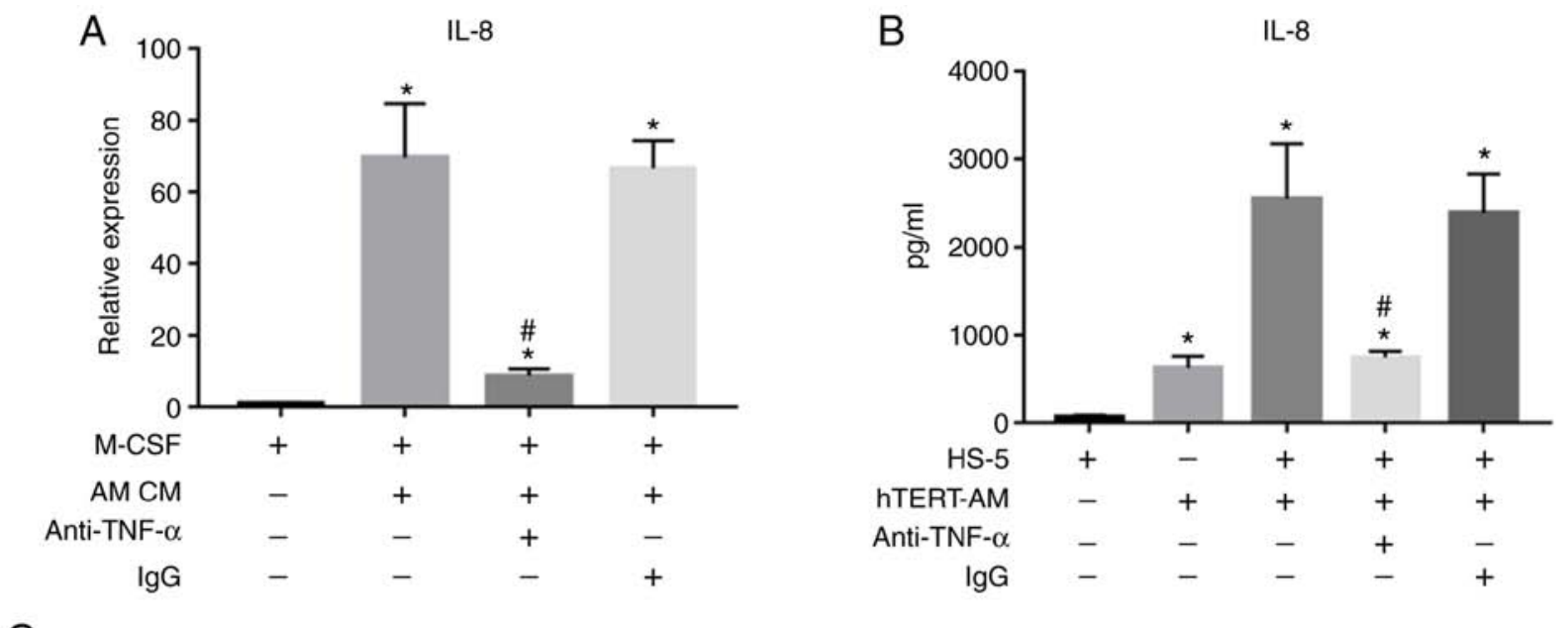

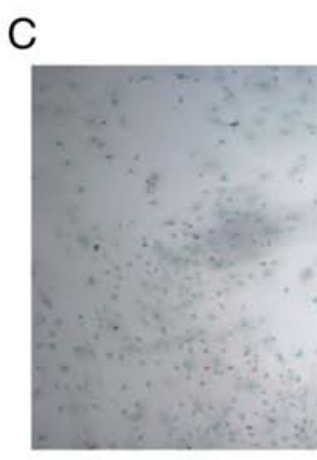

M-CSF

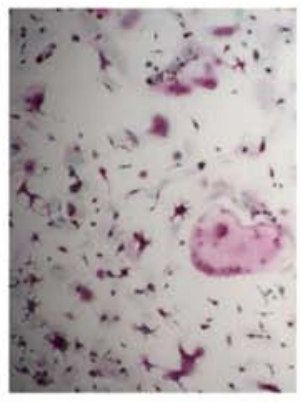

$\mathrm{M}-\mathrm{CSF}+\mathrm{IL}-8$

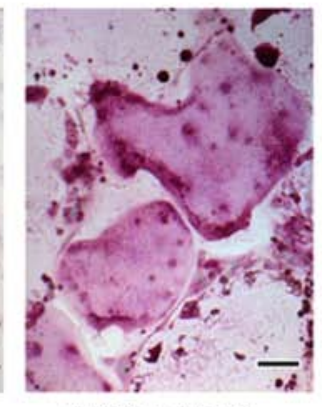

M-CSF+RANKL

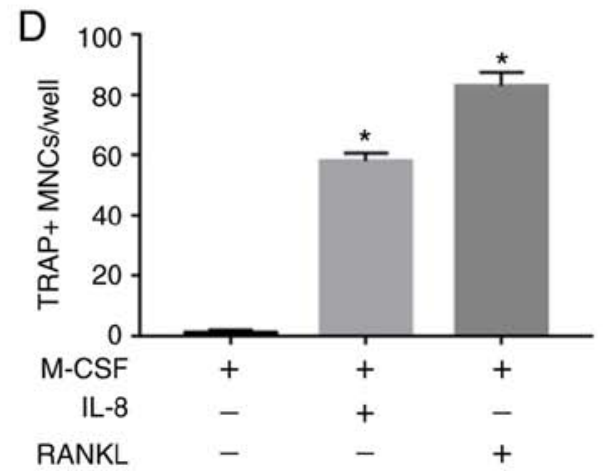

Figure 5. AM-derived TNF- $\alpha$ upregulated IL-8 expression in bone marrow stromal cells and IL-8 directly triggered osteoclastogenesis. (A) HS-5 cells were treated with CM from hTERT-AM with or without TNF- $\alpha$ antibody for $24 \mathrm{~h}$ and reverse transcription-quantitative polymerase chain reaction was performed to detect IL-8 expression in HS- 5 cells. ${ }^{*} \mathrm{P}<0.05$ vs. cells treated with M-CSF, ${ }^{\#} \mathrm{P}<0.05$ vs. wells containing M-CSF+AM/HS-5 CM. (B) HS-5 Cells and hTERT-AM were cultured independently or directly cocultured with or without TNF- $\alpha$ antibody $(50 \mathrm{ng} / \mathrm{ml})$ for $24 \mathrm{~h}$, IL-8 levels in the culture media were detected by ELISA. "P $<0.05$ vs. control, ${ }^{~} \mathrm{P}<0.05$ vs. coculture of HS-5 and hTERT-AM. (C) Osteoclast formation stimulated by recombinant IL- 8 or RANKL. Bone marrow-derived monocyte/macrophage precursor cells were cultured in osteoclastogenic medium with $25 \mathrm{ng} / \mathrm{ml} \mathrm{M}$-CSF, or in the same medium containing RANKL (50 ng/ml) or IL-8 (100 ng/ml). Scale bar, $250 \mu \mathrm{m}$. (D) TRAP positive MN cells ( $\geq 3$ nuclei) were counted as mature osteoclasts. "P<0.05 vs. cells treated with M-CSF. The experiment was performed in triplicate. IL, interleukin; M-CSF, macrophage-colony stimulating factors; TNF, tumor necrosis factor; RANKL, receptor activator of NF-KB ligand; AM, ameloblastoma; CM, conditioned media; TRAP, acid phosphatase 5, tartrate resistant; MN, multinucleated; Ig, immunoglobulin.

osteoclastogenesis, CM from hTERT-AM/HS-5 cocultures, with or without IL-8 or activin A neutralizing antibodies, were added to the culture of mouse BMMs in the presence of M-CSF. It was demonstrated that osteoclast formation provoked by the coculture medium was decreased either by neutralization of IL-8 or activin A (Fig. 4), which ascertained that the two proteins are involved in osteoclastogenesis induced by AM/BMSCs interactions and that IL- 8 seems to serve a more important role in osteoclastogenesis in AM.

AM-derived TNF- $\alpha$ upregulates $I L-8$ expression in BMSCs and $I L-8$ directly induces osteoclast formation. Studies have demonstrated that IL- 8 production can be induced in response to multiple signals including IL- $1 \alpha$, IL- $1 \beta$ and TNF- $\alpha(30,35)$. In the present study, TNF- $\alpha$ was observed to be highly expressed in hTERT-AM cells (Fig. 3A), therefore anti-TNF- $\alpha$ antibody was added to the culture medium of hTERT-AM cells to examine the effect of TNF- $\alpha$ on IL-8 expression in HS- 5 cells. The results demonstrated that neutralizing TNF- $\alpha$ significantly downregulated IL-8 expression in HS-5 cells induced by AM cells ( $\mathrm{P}<0.05$; Fig. 5A). ELISA analysis further indicated that the protein level of IL- 8 in the coculture medium of the two cell lines was significantly inhibited by addition of the anti-TNF- $\alpha$ antibody $(\mathrm{P}<0.05$; Fig. 5B). Additionally, it was also identified that IL-8 directly induced osteoclast formation in vitro (Fig. $5 \mathrm{C}$ and $\mathrm{D}$ ), which was consistent with previous studies $(36,37)$.

Upregulated IL-8 from the coculture system triggers $R A N K L$ expression in BMSCs. RT-qPCR was performed to examine whether AM-derived CM could induce RANKL expression in BMSCs. The results revealed that $\mathrm{CM}$ derived from hTERT-AM cells significantly increased RANKL expression in BMSCs $(\mathrm{P}<0.05)$. The expression of OPG, the decoy receptor of RANKL, was not altered (Fig. 6A). Additionally, adding OPG to the coculture medium slightly decreased osteoclast formation in mouse BMMs (Fig. 6B and C). Furthermore, it was identified that recombinant IL-8 induced RANKL level in BMSCs (Fig. 6D and E) and addition of anti-IL-8 antibody to AM-derived CM significantly decreased RANKL expression in BMSCs $(\mathrm{P}<0.05$; Fig. $6 \mathrm{E})$. These results indicate that hTERT-AM cells upregulated the expression of RANKL in HS-5 cells in an IL-8-dependent manner and RANKL further influenced osteoclast formation. 
A

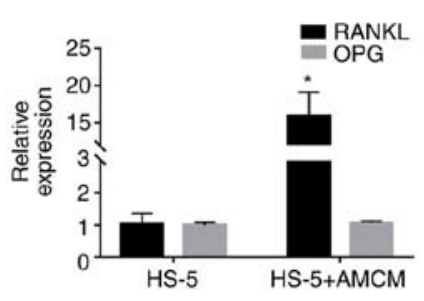

C

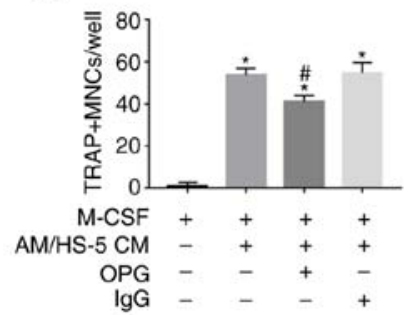

B

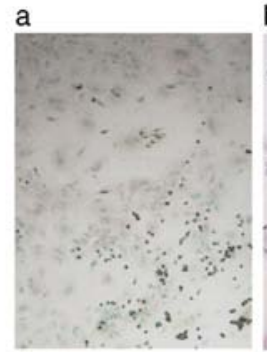

b

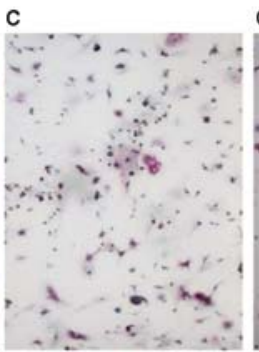

d

D

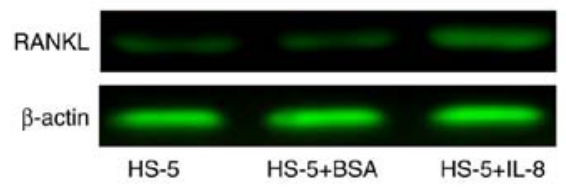

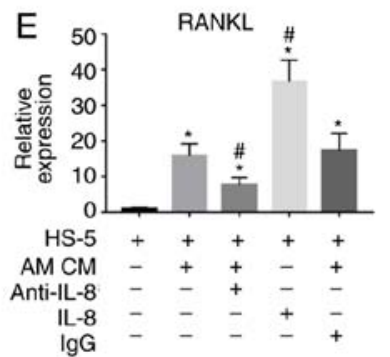

Figure 6. Upregulated IL-8 from the coculture system supported RANKL expression on bone marrow stromal cells. (A) HS-5 cells were cultured in the CM of hTERT-AM for $24 \mathrm{~h}$. RT-qPCR was performed to detect expressions of RANKL and OPG in HS-5 cells. * $<<0.05$ vs. untreated HS-5. (B) Mouse bone marrow-derived monocyte/macrophage precursor cells were cultured in osteoclastogenic medium with $25 \mathrm{ng} / \mathrm{ml} \mathrm{M}-\mathrm{CSF}$, or in the same medium containing the CM from HS-5/hTERT-AM cocultures at 1:1 dilution. OPG (100 ng/ml) was added to some of the CM-containing wells. (a) +M-CSF, (b) +M-CSF+AM/HS-5 CM, (c) +M-CSF+AM/HS-5 CM+OPG, (d) +M-CSF+AM/HS-5 CM+ IgG. Scale bar, $250 \mu \mathrm{m}$ (C) The number of TRAP+ MN cells ( $\geq 3$ nuclei) was indicated. ${ }^{\mathrm{P}}<0.05$ vs. cells treated with $\mathrm{M}-\mathrm{CSF},{ }^{*} \mathrm{P}<0.05$ vs. wells containing HS-5/hTERT-AM CM. (D) HS-5 cells were cultured with or without recombinant IL-8 $(100 \mathrm{ng} / \mathrm{ml})$ for $24 \mathrm{~h}$. Cells were harvested to analyze RANKL by western blotting. (E) HS-5 cells were treated with recombinant IL-8 $(100 \mathrm{ng} / \mathrm{ml})$ or CM from hTERT-AM with or without IL-8 antibody for $24 \mathrm{~h}$. RT-qPCR was performed to detect RANKL expression in HS-5 cells. $\mathrm{P}<0.05$ vs. HS-5, ${ }^{\text {}} \mathrm{P}<0.05$ vs. cells treated with hTERT-AM CM. The experiment was performed in triplicate. RT-qPCR, reverse transcription-quantitative polymerase chain reaction; IL, interleukin; BMSCs, bone marrow stromal cells; RANKL, receptor activator of NF- $\kappa$ B ligand; OPG, Osteoprotegerin; CM, conditioned medium; Ig, immunoglobulin; AM, ameloblastoma; TRAP, acid phosphatase 5, tartrate resistant; MN, multinucleated.

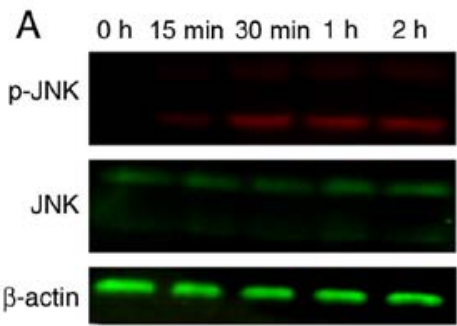

C

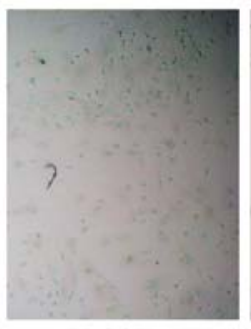

M-CSF
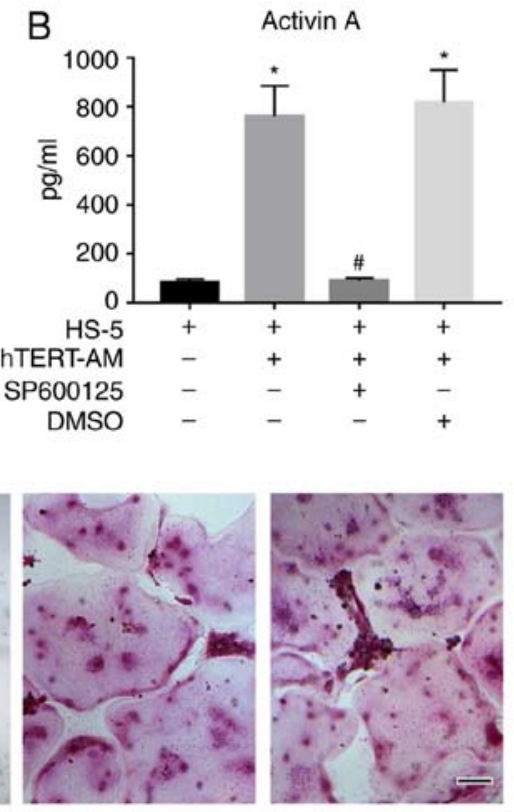

M-CSF+RANKL

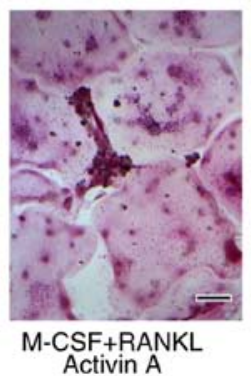

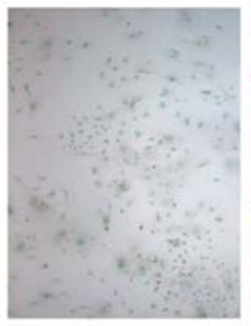

M-CSF+Activin A
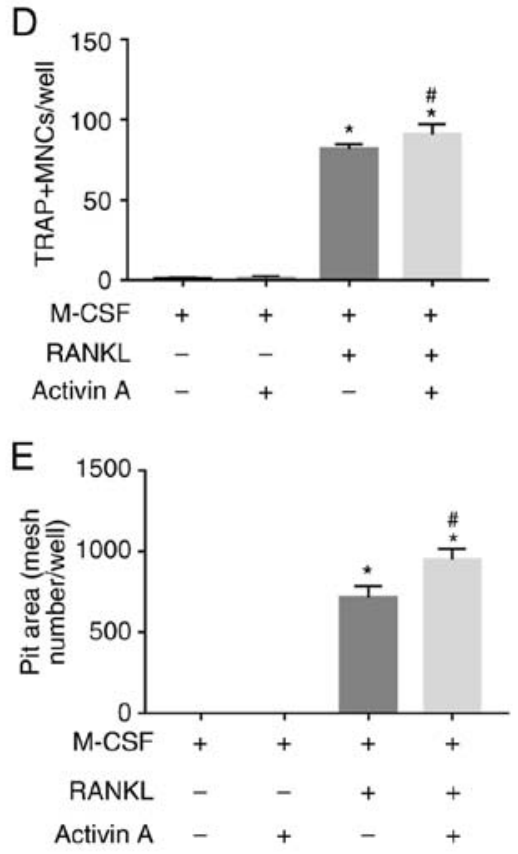

Figure 7. HS-5 cells secretion of activin A was induced by hTERT-AM cells via JNK pathway activation. (A) HS-5 cells were cocultured with fixed hTERT-AM cells and harvested at the indicated time points to analyze JNK phosphorylation by western blotting. (B) hTERT-AM cells and HS-5 cells were cocultured for $24 \mathrm{~h}$. In the last $15 \mathrm{~h}, \mathrm{JNK}$ inhibitor (SP600125, $10 \mu \mathrm{M}$ ) or $0.1 \%$ DMSO was added. The supernatants were analyzed for activin A levels by ELISA. * $<0.05$ vs. HS-5 CM, "P<0.05 vs. hTERT-AM/HS-5 CM. (C) Activin A stimulates RANKL-stimulated osteoclast differentiation. Mouse BMMs were differentiated to osteoclast with RANKL $(50 \mathrm{ng} / \mathrm{ml})$ and M-CSF $(25 \mathrm{ng} / \mathrm{ml})$ with or without activin A (50 ng/ml), and cultured for $3 \mathrm{days}$. (D) TRAP+ multinucleated cells ( $\geq 3$ nuclei) were counted. Scale bar, $250 \mu \mathrm{m}$. (E) BMMs were seeded onto $6 \mathrm{~mm}$-diameter dentin slices in 96 -well plates and cultured in medium with RANKL $(50 \mathrm{ng} / \mathrm{ml})$ and M-CSF (25 ng/ml) with or without activin A (50 ng/ml for 15 days). Culture media was changed every 2 days. Pit areas were measured by counting mesh numbers. ${ }^{*} \mathrm{P}<0.05$ vs. cells treated with $\mathrm{M}-\mathrm{CSF},{ }^{*} \mathrm{P}<0.05$ vs. wells containing M-CSF+RANKL. The experiment was performed in triplicate. JNK, c-Jun N-terminal kinase 1; M-CSF, macrophage-colony stimulating factor; RANKL, receptor activator of NF- $\mathrm{B}$ ligand; BMMs, bone marrow-derived monocyte/macrophage precursor cells; TRAP, acid phosphatase 5, tartrate resistant; AM, ameloblastoma; CM, conditioned medium. 
JNK activation is associated with AM-induced secretion of activin A in BMSCs. Previous studies demonstrated that activin A secretion was regulated by p38-dependent and JNK-dependent pathways, and that a highly conserved c-Jun-binding sequence was present in the INH $\beta$ A promoter (38). Whether activation of the JNK pathway was associated with activin A production was therefore investigated by coculture of HS-5 cells and hTERT-AM cells. The results indicated that direct coculture of the two cell lines activated the JNK pathway, as phosphorylation of JNK was observed in HS-5 cells in the presence of fixed AM cells (Fig. 7A). It was also demonstrated that adding the specific JNK inhibitor SP600125 significantly reduced activin A secretion in the coculture medium $(\mathrm{P}<0.05$; Fig. 7B). Furthermore, although activin $\mathrm{A}$ itself did not stimulate osteoclast formation, it did slightly support RANKL to induce osteoclastogenesis (Fig. 7C and D). Furthermore, the pit formation assay revealed that the area of resorption pits on the dentin slices treated with RANKL and activin A was about 1.3-fold greater than those seeded with RANKL alone (Fig. 7E). This suggests that activin $\mathrm{A}$ acts as a cofactor of RANKL to induce osteoclast formation and function and has a more effective triggering function of osteoclasts.

\section{Discussion}

The present study revealed that interactions between AM cells and BMSCs trigger osteoclastogenesis by upregulating IL-8 and activin A. Production of IL- 8 in BMSCs was enhanced by AM-derived TNF- $\alpha$ and IL- 8 further induced osteoclast formation directly or by upregulating RANKL expression in BMSCs. It was also demonstrated that activin A secretion was stimulated in BMSCs via activation of the JNK pathway in the presence of AM cells; furthermore, activin A acted as a cofactor of RANKL in stimulating osteoclast formation and function.

RANKL is known as an essential factor for osteoclast differentiation. It can be released in soluble form from tumor cells and can stimulate osteoclast formation directly in the absence of stromal cells (39). Sandra et al (3) revealed that 10X CM of AM-1 cells, an AM cell line, stimulated osteoclastogenesis because of RANKL secretion. However, the results of the present study demonstrated only a slight increase in osteoclast formation of osteoclast precursors in response to AM cells and no evidence of RANKL expression in AM cells. Yoshimoto et al (40) also failed to observe detectable expression of RANKL in AM cells. Interestingly, clear expression of IL-8 was observed in AM cells and neutralization of IL-8 prevented osteoclastogenesis induced by the CM of AM cells (data not shown), suggesting that tumor-derived IL-8 is a key factor that directly induces osteoclast differentiation in AM and that the soluble RANKL in the $1 \mathrm{X} \mathrm{CM}$ of AM cells is too low to induce osteoclastogenesis.

Previous studies have emphasized the importance of tumor-microenvironment interactions in tumor cell growth and invasion as well as osteoclastogenesis in a variety of tumors $(15,16,41)$. For example, adhesion of myeloma cells to BMSCs stimulated IL-6 expression by BMSCs, which was further involved in modulating tumor growth and invasiveness. Interactions between multiple myeloma cells and stromal cells induced osteoclastogenesis by upregulating IL-8 expression in stromal cells (13). Consistent with these findings, Fuchigami et al (30) demonstrated that reciprocal cell-cell interactions between tumor cells and stromal fibroblasts resulted in increased production of IL- 6 and IL- 8 by fibroblasts, and increased proliferation of AM cells. In the present study, it was observed that the interaction between AM cells and BMSCs led to augmented secretion of IL- 8 and activin A.

IL-8, a member of the CXC chemokine family, was originally described as a chemoattractant of neutrophils (42). It is highly expressed in a variety of human cancer cells with high metastatic potential (36). Overexpression of IL-8 not only correlates with tumor growth, angiogenesis and metastasis $(43,44)$, but also serves a critical role in osteoclast formation $(36,37,45)$. To investigate the role of upregulated IL-8 in the coculture system in osteoclastogenesis, the neutralizing anti-IL8 antibody was tested on osteoclast formation. The findings demonstrated a dramatically reduced osteoclast formation induced by AM/BMSCs coculture medium. These findings again verified that IL-8 is a vital regulator of osteoclastogenesis in AM. According to previous studies, IL-8 production can be induced in response to multiple signals including IL- $1 \alpha$, IL- $1 \beta$ and TNF- $\alpha(30,35)$. TNF- $\alpha$ is a proinflammatory cytokine that has been implicated in inflammatory and immune responses (46). It was demonstrated to regulate tumor growth and invasiveness by upregulating IL-6 and matrix metalloproteinase-9 in AM cells (34). The expression of TNF- $\alpha$ was increased in AM cells compared with in BMSCs, prompting investigation of the role of tumor-derived TNF- $\alpha$ in IL- 8 secretion in AM. The data demonstrated that neutralizing TNF- $\alpha$ partially inhibited IL- 8 production in hTERT-AM/HS-5 coculture, indicating that AM-derived TNF- $\alpha$ is critical in modulating osteoclastogenesis through upregulation of IL-8 secretion in BMSCs.

Previous studies demonstrated that RANKL-positive cells were more commonly distributed throughout the stroma than in tumor cells in AM $(40,47,48)$. The results of the present study indicated that RANKL mRNA was positively expressed in AM tissues rather than in AM cells, confirming that stromal cells are the major source of RANKL in AM. In addition, hTERT-AM/HS-5 coculture increased RANKL expression in BMSCs and RANKL-neutralization suppressed osteoclast formation induced by the coculture medium. These findings verified the role of stromal-derived RANKL in osteoclastogenesis in AM. Similarly, studies demonstrated that multiple myeloma cells (21-24) can stimulate osteoclastogenesis by increasing RANKL production in BMSCs and osteoblasts. Furthermore, RANKL is triggered by multiple bone-resorbing factors including parathyroid hormone-associated protein, IL-1, IL-6, IL-8, IL-11 and IL-17 $(14,15,29)$. Interestingly, neutralization of IL-8 in the AM/BMSCs coculture medium suppressed RANKL expression in BMSCs, suggesting that interactions between the AM cells and BMSCs induced RANKL expression through an IL-8-dependent pathway.

Activin $A$ is a member of the transforming growth factor (TGF)- $\beta$ superfamily, which was identified as a regulator of the pituitary follicular stimulating hormone (49), embryogenesis (50), cell proliferation $(51)$, apoptosis $(51,52)$ and differentiation (53). Interestingly, this factor was also 
proposed to be involved in bone remodeling because of its dual role in stimulating osteoclast formation $(33,54)$ and inhibiting osteoblast differentiation (25). The results of the present study demonstrated that activin A secretion was increased by direct interactions between AM cells and BMSCs. As previous studies revealed that a highly conserved c-Jun-binding sequence was present in the INH $\beta$ A promoter (38) and that cell-to-cell contact triggers activation of the JNK signaling pathway (55), the role of the JNK pathway on activin A production by AM/BMSC coculture was further investigated. The results indicated that adhesion between BMSCs and AM cells activated the JNK pathway in BMSCs and the JNK inhibitor reduced activin A secretion in the coculture, confirming involvement of the JNK pathway in activin A production by BMSCs in response to AM cells. Additionally, neutralization of activin A in coculture resulted in decreased osteoclast formation. Furthermore, although activin A could only slightly enhance osteoclast formation in BMMs in the presence of RANKL, it increased the potential of osteoclasts to resorb calcified tissues, suggesting that activin $\mathrm{A}$ acts as a synergist for RANKL, which serves a greater role in stimulating osteoclast function than osteoclast formation. However, further research should be done in the future to elucidate the possible mechanisms of this phenomenon.

The limitation of the present study may be that $\mathrm{CM}$ from human cells is used to stimulate the BMMs from mice to evaluate their ability to induce osteoclast formation. Indeed, it would be more convincing if human BMMs were used in this experiment. However, normal human BMMs are hard to obtain in the authors' institution. Previous studies have conducted cocultures of cells from humans and other species including mice (3,56-58), rats (59) or rabbits (60) to investigate their interactions. This approach was therefore used in the current study. As expected, it was identified that the coculture medium from human AM cells and BMSCs increased osteoclast formation from mouse BMMs. Detailed analysis of organs, tissues, cells and molecules exhibits a number of similarities between humans and mice, ranging from embryonic development to diseases including diabetes and cancer, despite their striking anatomical difference. In addition, for $\sim 99 \%$ of mouse genes, a counterpart can be identified in the human genome, which indicated high homologly between the mouse and human genomes (61). Furthermore, most cytokines, including fibroblast growth factor (62), and neurotrophin [brain derived neurotrophic growth factor (DNF), Glial cell DNF and ciliary neurotrophic factor) (63), TGF- $\beta$ (64)], are highly conserved molecules, exhibiting strong cross-species bioactivity among different species. These results further support the feasibility of this method. However, there are a few exceptions. For example, human IL-6 can bind to the human IL-6 receptor (IL-6R) and the mouse IL-6R, while mouse IL-6 only binds to the mouse IL-6R (57). Therefore, to overcome this potential limitation, the authors' intend to choose cells from the same species to check their communication in future research.

In conclusion, the results of the present study support that tumor-microenvironment interactions induce osteoclastogenesis and the process was modulated by upregulated IL-8, and activin A. IL-8 is a key regulator of osteoclast formation, which not only induced osteoclast differentiation directly but also triggered RANKL expression. In combination with activin A, which acted as a synergist of RANKL, a favorable microenvironment was established for AM invasion in the bone.

\section{Acknowledgements}

Not applicable.

\section{Funding}

The present study was supported by the Science and Technology Planning Project of Guangdong Province (grant number 2017A020211025).

\section{Availability of data and materials}

All data of this study are included in this article.

\section{Authors' contributions}

QT and XL conceived and designed the study. XL, ZC and TL performed the experiments. PL analyzed the data. XL and ZC wrote the manuscript.

\section{Ethics approval and consent to participate}

The study was approved by the Ethical Committee of the Guanghua School of Stomatology, Hospital of Stomatology and Sun Yat-sen University [Guangzhou, China; ERC-(2017)-5] and the Institutional Animal Care and Use Committee of Sun Yat-sen University (IACUC-DB-2017-0605).

\section{Patient consent for publication}

Patient consent for publication was obtained

\section{Competing interests}

The authors declare that they have no competing interests.

\section{References}

1. Jhamb T and Kramer JM: Molecular concepts in the pathogenesis of ameloblastoma: Implications for therapeutics. Exp Mol Pathol 97: 345-353, 2014.

2. Wright JM and Vered M: Update from the 4th edition of the world health organization classification of head and neck tumours: Odontogenic and maxillofacial bone tumors. Head Neck Pathol 11: 68-77, 2017.

3. Sandra F, Hendarmin L, Kukita T, Nakao Y, Nakamura N and Nakamura S: Ameloblastoma induces osteoclastogenesis: A possible role of ameloblastoma in expanding in the bone. Oral Oncol 41: 637-644, 2005.

4. Ong'uti MN, Cruchley AT, Howells GL and Williams DM: Ki-67 antigen in ameloblastomas: Correlation with clinical and histological parameters in 54 cases from Kenya. Int J Oral Maxillofac Surg 26: 376-379, 1997.

5. Sandra F, Mitsuyasu T, Nakamura N, Shiratsuchi Y and Ohishi M: Immunohistochemical evaluation of PCNA and Ki-67 in ameloblastoma. Oral Oncol 37: 193-198, 2001.

6. Sandra F, Nakamura N, Mitsuyasu T, Shiratsuchi Y and Ohishi M: Two relatively distinct patterns of ameloblastoma: An anti-apoptotic proliferating site in the outer layer (periphery) and a pro-apoptotic differentiating site in the inner layer (centre). Histopathology 39: 93-98, 2001. 
7. Luo HY, Yu SF and Li TJ: Differential expression of apoptosis-related proteins in various cellular components of ameloblastomas. Int J Oral Maxillofac Surg 35: 750-755, 2006.

8. Jiang C, Zhang Q, Shanti RM, Shi S, Chang TH, Carrasco L, Alawi F and Le AD: Mesenchymal stromal cell-derived interleukin-6 promotes epithelial-mesenchymal transition and acquisition of epithelial stem-like cell properties in ameloblastoma epithelial cells. Stem Cells 35: 2083-2094, 2017.

9. Zhang L, Zeng D, Huang H, Wang J, Tao Q, Pan C, Xu J, Zhang B and Wang A: Tissue inhibitor of metalloproteinase-2 inhibits ameloblastoma growth in a new mouse xenograft disease model. J Oral Pathol Med 39: 94-102, 2010.

10. Zhang B, Zhang J, Huang HZ, Xu ZY and Xie HL: Expression and role of metalloproteinase- 2 and endogenous tissue regulator in ameloblastoma. J Oral Pathol Med 39: 219-222, 2010.

11. Wang A, Zhang B, Huang H, Zhang L, Zeng D, Tao Q, Wang J and Pan C: Suppression of local invasion of ameloblastoma by inhibition of matrix metalloproteinase-2 in vitro. BMC Cancer 8 : $182,2008$.

12. Martin TJ: Manipulating the environment of cancer cells in bone: A novel therapeutic approach. J Clin Invest 110: 1399-1401, 2002.

13. Herrero AB, García-Gómez A, Garayoa M, Corchete LA, Hernández JM, San Miguel J and Gutierrez NC: Effects of IL-8 Up-regulation on cell survival and osteoclastogenesis in multiple myeloma. Am J Pathol 186: 2171-2182, 2016.

14. Sottnik JL and Keller ET: Understanding and targeting osteoclastic activity in prostate cancer bone metastases. Curr Mol Med 13: 626-639, 2013.

15. Kovacic N, Croucher PI and McDonald MM: Signaling between tumor cells and the host bone marrow microenvironment. Calcif Tissue Int 94: 125-139, 2014.

16. Mundy GR: Metastasis to bone: Causes, consequences and therapeutic opportunities. Nat Rev Cancer 2: 584-593, 2002.

17. Azim $\mathrm{H}$ and Azim HA Jr: Targeting RANKL in breast cancer: Bone metastasis and beyond. Expert Rev Anticancer Ther 13: 195-201, 2013.

18. Chen G, Sircar K, Aprikian A, Potti A, Goltzman D and Rabbani SA: Expression of RANKL/RANK/OPG in primary and metastatic human prostate cancer as markers of disease stage and functional regulation. Cancer 107: 289-298, 2006.

19. Croucher PI, Shipman CM, Lippitt J, Perry M, Asosingh K, Hijzen A, Brabbs AC, van Beek EJ, Holen I, Skerry TM, et al: Osteoprotegerin inhibits the development of osteolytic bone disease in multiple myeloma. Blood 98: 3534-3540, 2001

20. Sezer O, Heider U, Jakob C, Eucker J and Possinger K: Human bone marrow myeloma cells express RANKL. J Clin Oncol 20 : 353-354, 2002

21. Farrugia AN, Atkins GJ, To LB, Pan B, Horvath N, Kostakis P, Findlay DM, Bardy $\mathrm{P}$ and Zannettino AC: Receptor activator of nuclear factor-kappaB ligand expression by human myeloma cells mediates osteoclast formation in vitro and correlates with bone destruction in vivo. Cancer Res 63: 5438-5445, 2003.

22. Giuliani N, Bataille R, Mancini C, Lazzaretti M and Barillé S: Myeloma cells induce imbalance in the osteoprotegerin/osteoprotegerin ligand system in the human bone marrow environment. Blood 98: 3527-3533, 2001.

23. Pearse RN, Sordillo EM, Yaccoby S, Wong BR, Liau DF, Colman N, Michaeli J, Epstein J and Choi Y: Multiple myeloma disrupts the TRANCE/osteoprotegerin cytokine axis to trigger bone destruction and promote tumor progression. Proc Natl Acad Sci USA 98: 11581-11586, 2001.

24. Shipman CM and Croucher PI: Osteoprotegerin is a soluble decoy receptor for tumor necrosis factor-related apoptosis-inducing ligand/Apo2 ligand and can function as a paracrine survival factor for human myeloma cells. Cancer Res 63: 912-916, 2003.

25. Vallet S, Mukherjee S, Vaghela N, Hideshima T, Fulciniti M, Pozzi S, Santo L, Cirstea D, Patel K, Sohani AR, et al: Activin a promotes multiple myeloma-induced osteolysis and is a promising target for myeloma bone disease. Proc Natl Acad Sci USA 107: 5124-5129, 2010.

26. Renema N, Navet B, Heymann MF, Lezot F and Heymann D: RANK-RANKL signalling in cancer. Biosci Rep 36: pii: e00366, 2016.

27. Chikatsu N, Takeuchi Y, Tamura Y, Fukumoto S, Yano K, Tsuda E, Ogata E and Fujita T: Interactions between cancer and bone marrow cells induce osteoclast differentiation factor expression and osteoclast-like cell formation in vitro. Biochem Biophys Res Commun 267: 632-637, 2000.
28. Sisay M, Mengistu G and Edessa D: The RANK/RANKL/OPG system in tumorigenesis and metastasis of cancer stem cell: Potential targets for anticancer therapy. Onco Targets Ther 10: 3801-3810, 2017.

29. Wada T, Nakashima T, Hiroshi $\mathrm{N}$ and Penninger JM: RANKL-RANK signaling in osteoclastogenesis and bone disease. Trends Mol Med 12: 17-25, 2006.

30. Fuchigami T,Kibe T, Koyama H, Kishida S, Iijima M,Nishizawa Y, Hijioka H, Fujii T, Ueda M, Nakamura N, et al: Regulation of IL-6 and IL- 8 production by reciprocal cell-to-cell interactions between tumor cells and stromal fibroblasts through IL-1 $\alpha$ in ameloblastoma. Biochem Biophys Res Commun 451: 491-496, 2014.

31. Tao Q, Lv B, Qiao B, Zheng CQ and Chen ZF: Immortalization of ameloblastoma cells via reactivation of telomerase function: Phenotypic and molecular characteristics. Oral Oncol 45: e239-e244, 2009

32. Wani MR, Fuller K, Kim NS, Choi Y and Chambers T: Prostaglandin E2 cooperates with TRANCE in osteoclast induction from hemopoietic precursors: Synergistic activation of differentiation, cell spreading, and fusion. Endocrinology 140: 1927-1935, 1999.

33. Fuller K, Bayley KE and Chambers TJ: Activin A is an essential cofactor for osteoclast induction. Biochem Biophys Res Commun 268: 2-7, 2000.

34. Ohta K, Naruse T, Ishida Y, Shigeishi H, Nakagawa T, Fukui A, Nishi H, Sasaki K, Ogawa I and Takechi M: TNF- $\alpha$-induced IL-6 and MMP-9 expression in immortalized ameloblastoma cell line established by hTERT. Oral Dis 23: 199-209, 2017.

35. Kline M, Donovan K, Wellik L, Lust C, Jin W, Moon-Tasson L, Xiong Y, Witzig TE, Kumar S, Rajkumar SV and Lust JA: Cytokine and chemokine profiles in multiple myeloma; significance of stromal interaction and correlation of IL- 8 production with disease progression. Leuk Res 31: 591-598, 2007.

36. Bendre MS, Margulies AG, Walser B, Akel NS, Bhattacharrya S, Skinner RA, Swain F, Ramani V, Mohammad KS, Wessner LL, et al: Tumor-derived interleukin-8 stimulates osteolysis independent of the receptor activator of nuclear factor-kappaB ligand pathway. Cancer Res 65: 11001-11009, 2005.

37. Bendre MS, Montague DC, Peery T, Akel NS, Gaddy D and Suva LJ: Interleukin-8 stimulation of osteoclastogenesis and bone resorption is a mechanism for the increased osteolysis of metastatic bone disease. Bone 33: 28-37, 2003.

38. Tanimoto K, Yoshida E, Mita S, Nibu Y, Murakami K and Fukamizu A: Human activin betaA gene. Identification of novel 5' exon, functional promoter, and enhancers. J Biol Chem 271: 32760-32769, 1996.

39. Lacey DL, Timms E, Tan HL, Kelley MJ, Dunstan CR, Burgess T, Elliott R, Colombero A, Elliott G, Scully S, et al: Osteoprotegerin ligand is a cytokine that regulates osteoclast differentiation and activation. Cell 93: 165-176, 1998

40. Yoshimoto S, Morita H, Matsubara R, Mitsuyasu T, Imai Y, Kajioka S, Yoneda M, Ito Y, Hirofuji T, Nakamura S and Hirata M: Surface vacuolar ATPase in ameloblastoma contributes to tumor invasion of the jaw bone. Int J Oncol 48: 1258-1270, 2016.

41. Suva LJ, Washam C, Nicholas RW and Griffin RJ: Bone metastasis: Mechanisms and therapeutic opportunities. Nat Rev Endocrinol 7: 208-218, 2011.

42. Yoshimura T, Matsushima K, Tanaka S, Robinson EA, Appella E, Oppenheim JJ and Leonard EJ: Purification of a human monocyte-derived neutrophil chemotactic factor that has peptide sequence similarity to other host defense cytokines. Proc Natl Acad Sci USA 84: 9233-9237, 1987.

43. Waugh DJ and Wilson C: The interleukin-8 pathway in cancer. Clin Cancer Res 14: 6735-6741, 2008.

44. Kim SJ, Uehara H, Karashima T, McCarty M, Shih N and Fidler IJ: Expression of interleukin-8 correlates with angiogenesis, tumorigenicity, and metastasis of human prostate cancer cells implanted orthotopically in nude mice. Neoplasia 3: 33-42, 2001.

45. Hwang YS, Lee SK, Park KK and Chung WY: Secretion of IL-6 and IL-8 from lysophosphatidic acid-stimulated oral squamous cell carcinoma promotes osteoclastogenesis and bone resorption. Oral Oncol 48: 40-48, 2012.

46. Baud V and Karin M: Signal transduction by tumor necrosis factor and its relatives. Trends Cell Biol 11: 372-377, 2001

47. da Silva TA, Batista AC, Mendonca EF, Leles CR, Fukada S and Cunha FQ: Comparative expression of RANK, RANKL, and OPG in keratocystic odontogenic tumors, ameloblastomas, and dentigerous cysts. Oral Surg Oral Med Oral Pathol Oral Radiol Endod 105: 333-341, 2008. 
48. Siar $\mathrm{CH}$, Tsujigiwa $\mathrm{H}$, Ishak I, Hussin $\mathrm{NM}$, Nagatsuka $\mathrm{H}$ and $\mathrm{Ng} \mathrm{KH}$ : RANK, RANKL, and OPG in recurrent solid/multicystic ameloblastoma: Their distribution patterns and biologic significance. Oral Surg Oral Med Oral Pathol Oral Radiol 119: 83-91, 2015.

49. Vale W, Rivier J, Vaughan J, McClintock R, Corrigan A, Woo W, Karr D and Spiess J: Purification and characterization of an FSH releasing protein from porcine ovarian follicular fluid. Nature 321: 776-779, 1986.

50. Xia Y and Schneyer AL: The biology of activin: Recent advances in structure, regulation and function. J Endocrinol 202: 1-12, 2009.

51. Chen YG, Lui HM, Lin SL, Lee JM and Ying SY: Regulation of cell proliferation, apoptosis, and carcinogenesis by activin. Exp Biol Med (Maywood) 227: 75-87, 2002.

52. Chen YG, Wang Q, Lin SL, Chang CD, Chuang J and Ying SY: Activin signaling and its role in regulation of cell proliferation, apoptosis, and carcinogenesis. Exp Biol Med (Maywood) 231: 534-544, 2006.

53. Nicks KM, Perrien DS, Akel NS, Suva LJ and Gaddy D Regulation of osteoblastogenesis and osteoclastogenesis by the other reproductive hormones, activin and inhibin. Mol Cell Endocrinol 310: 11-20, 2009.

54. Kajita T, Ariyoshi W, Okinaga T, Mitsugi S, Tominaga $\mathrm{K}$ and Nishihara T: Mechanisms involved in enhancement of osteoclast formation by activin-A. J Cell Biochem 119: 6974-6985, 2018.

55. Snider JL, Allison C, Bellaire BH, Ferrero RL and Cardelli JA: The betal integrin activates JNK independent of CagA, and JNK activation is required for Helicobacter pylori $\mathrm{CagA}^{+}$-induced motility of gastric cancer cells. J Biol Chem 283: 13952-13963, 2008.

56. Ohshiba $T$, Miyaura $C$, Inada $M$ and Ito A: Role of RANKL-induced osteoclast formation and MMP-dependent matrix degradation in bone destruction by breast cancer metastasis. Br J Cancer 88: 1318-1326, 2003.

57. Zheng Y, Chow SO, Boernert K, Basel D, Mikuscheva A, Kim S, Fong-Yee C, Trivedi T, Buttgereit F, Sutherland RL, et al: Direct crosstalk between cancer and osteoblast lineage cells fuels metastatic growth in bone via auto-amplification of IL-6 and RANKL signaling pathways. J Bone Miner Res 29: 1938-1949, 2014.
58. Bussard KM, Venzon DJ and Mastro AM: Osteoblasts are a major source of inflammatory cytokines in the tumor microenvironment of bone metastatic breast cancer. J Cell Biochem 111: 1138-1148, 2010

59. Sohara Y, Shimada H, Minkin C, Erdreich-Epstein A, Nolta JA and DeClerck YA: Bone marrow mesenchymal stem cells provide an alternate pathway of osteoclast activation and bone destruction by cancer cells. Cancer Res 65: 1129-1135, 2005.

60. Qian Y and Huang HZ: The role of RANKL and MMP-9 in the bone resorption caused by ameloblastoma. J Oral Pathol Med 39: $592-598,2010$

61. Guénet JL: The mouse genome. Genome Res 15: 1729-1740, 2005.

62. Cilvik SN, Wang JI, Lavine KJ, Uchida K, Castro A, Gierasch CM, Weinheimer CJ, House SL, Kovacs A, Nichols CG and Ornitz DM: Fibroblast growth factor receptor 1 signaling in adult cardiomyocytes increases contractility and results in a hypertrophic cardiomyopathy. PLoS One 8: e82979, 2013.

63. Sunagar K, Fry BG, Jackson TN, Casewell NR, Undheim EA Vidal N, Ali SA, King GF, Vasudevan K, Vasconcelos V and Antunes A: Molecular evolution of vertebrate neurotrophins: Co-option of the highly conserved nerve growth factor gene into the advanced snake venom arsenalf. PLoS One 8: e81827, 2013.

64. Shen J, Li S and Chen D: TGF- $\beta$ signaling and the development of osteoarthritis. Bone Res 2: pii: 14002, 2014.

This work is licensed under a Creative Commons Attribution-NonCommercial-NoDerivatives 4.0 International (CC BY-NC-ND 4.0) License. 